RESEARCH REPORT

\title{
Avoidable mortality in Europe (1980-1997): a comparison of trends
}

\author{
H F Treurniet, H C Boshuizen, P P M Harteloh
}

J Epidemiol Community Health 2004;58:290-295. doi: 10.1136/jech.2002.006452

See end of article for authors' affiliations .....................

Correspondence to:

Dr H F Treurniet, National Institute of Public Health and the Environment, PO box 1, 3720 BA Bilthoven, Netherlands; henriette.treurniet@rivm.nl

Accepted for publication 11 June 2003 n 1976, Rutstein et al systematically identified health outcomes (death, disease, and disability) that may be considered avoidable, given the medical knowledge available then. "Avoidable" here means that the excess occurrence of these outcomes points to potential problems in health care. The lists with outcomes were updated only once, in $1980,{ }^{2}$ so they are now almost 25 years old. Despite their age, Rutstein's lists are still used to study variations in avoidable mortality, for example between regions, between countries, or in time. These variations provide a signal to healthcare workers and policy makers, which may prompt further investigation.

Avoidable mortality has been analysed in individual countries $^{3-6}$ and also within Europe. ${ }^{7-12}$ Only a few studies have dealt with international trends in mortality. ${ }^{911}{ }^{13}$ One of the conclusions of these studies is that the reduction of mortality was generally greater for avoidable causes than for all cause or other mortality. Charlton et al concluded this from a study of the period 1950-1980'; Simonato et al, from an analysis of the period 1955-1994 ${ }^{11}$; and Kjellstrand et al, from a study on trends between 1980 and $1990 .^{13}$

We studied international variations in mortality in Europe for a broad range of causes in the period 1980-1997. Our first aim was to examine whether avoidable mortality is still declining faster than other-that is, non-avoidable mortality (which would indicate that the term "avoidable" is still warranted). Our second aim was to study the trends in avoidable mortality by cause of death and by country in the more recent years, 1989-1997.

\section{METHODS}

We studied 19 avoidable causes of death for those 0-64 years old (table 1). Our selection was based on the selection from the European Community (EC) Working Group. ${ }^{7}$ They chose causes of death from Rutstein's lists $(1976)^{1}$ representing the outcomes of both healthcare interventions (appendicitis, Hodgkin's disease, etc) and national health policies (for example, lung cancer and liver cirrhosis). We did not study all the causes of death in the EC Working Group's selection because of insufficient numbers of deaths in some countries that were associated with abdominal hernia, maternal deaths, and some infectious diseases (typhoid, whooping cough, tetanus, measles, and osteomyelitis).

Age and sex specific mortality rates were derived from the WHO Mortality Database, WHO Geneva, version of 14 July 2000. Perinatal mortality/1000 deliveries was available from the Health for All (HFA) Statistical Database, WHO Regional Office for Europe, Copenhagen, Denmark, version of July 2000. Data from 17 countries were used (table 2).

Analysis was restricted to mortality below the age of 65 . We calculated the age and sex standardised mortality rates using the European standard population ${ }^{14}$ and weighting both sexes equally. Directly standardised rates were plotted against the calendar year for each country. SAS PROC MIXED was used to fit a multilevel (random slope) model to the data. We used this model as we thought there might be both a general Europe-wide trend and individual differences in trends between countries. Both effects are modelled simultaneously in a random slope model, which makes it easy to test whether trends in individual countries differ from the general trend. We preferred modelling of directly standardised rates over Poisson regression of age and sex specific data, as the latter yields less comparable, indirectly standardised rates. ${ }^{15}$

We used the following model:

- $M_{i t}=\alpha_{0}+\alpha_{i}+\beta_{0} t+\epsilon_{i t}$, where $M_{i t}$ is the standardised mortality rate in year $t$ for country $i, \alpha_{0}$ and $\beta_{0}$ are the intercept and slope for all countries on average, $\alpha_{i}$ and $\beta_{i}$ are the 


\begin{tabular}{|lll|}
\hline \multicolumn{3}{l}{ Table 1 Selected causes of death and ICD codes } \\
\hline Cause of death & ICD 8 & ICD 9 \\
\hline Tuberculosis & $010-019$ & $010-018,137$ \\
Appendicitis & $540-543$ & $540-543$ \\
Lung cancer & 162 & 162 \\
Bladder cancer & 188 & 188 \\
Liver cancer & 155 & 155.0 \\
Testis cancer & 186 & 186 \\
Liver cirrhosis & 571 & 571 \\
Perinatal & $760-778$ & $760-779$ \\
Motor vehicle accidents & E810-823 & E810-819 \\
Skin cancer & $172-173$ & $172-173$ \\
Breast cancer & 174 & 174 \\
Cervix cancer & 180 & 180 \\
Hodgkin's disease & 201 & 201 \\
CVA/hypertension & $400-404,430-8$ & $401-405,430-438$ \\
Asthma/bronchitis/emphysema & $490-493$ & $490-493$ \\
Cholelithiasis/cholecystitis & $574-575$ & $574-575.1,576.1$ \\
Pneumonia/influenza & $481-486$ & $480-486,487$ \\
Leukaemia & $204-208$ & $204-208$ \\
Chronic rheumatic heart disease & $393-398$ & $390-398,242$ \\
\hline ICD, International Classification of Diseases of the World Health Organisation; CVA, cardiovascular accident. \\
\hline
\end{tabular}

deviations of the intercept and slope of country $i$ from this average, and $\epsilon_{i j}$ is an error term with mean 0 . We used this model and Bonferroni adjustment to calculate which countries had a $\beta_{i}$ that differed significantly from 0 . In other words, we indicated which countries have mortality rates that decreased significantly faster or slower than the average decrease over all countries.

As important extra-Poisson variation existed in the data, we calculated the variance $\epsilon_{i t}$ as:

$$
\begin{aligned}
\operatorname{Var}\left(\varepsilon_{i t}=\right. & {\left[\frac{1}{n} S S E_{i}-\frac{1}{n} \sum_{t} E\left(\operatorname{var}_{P}(i, t)\right)\right] } \\
& +E\left(\operatorname{var}_{P}(i, t)\right)
\end{aligned}
$$

where $\mathrm{E}\left(\operatorname{var}_{P}\right)$ is the expected variance based on the Poisson distribution as calculated from the numbers of death, SSE is the sum of the squared residuals around the regression line, and $n$ is the number of years for which a standardised rate is available.

The relative decrease of mortality was studied with similar models using $\log \left(M_{i t}\right)$ as a dependent variable.

In many cases, the country specific slope $\beta_{i}$ correlated negatively (and statistically significantly) with the country

Table 2 Countries under study and the periods for which mortality data were available

\begin{tabular}{ll}
\hline Country & Period in which data were available \\
\hline Belgium & $1980-1994$ \\
Denmark & $1980-1996$ \\
Germany & $1980-1998$ \\
Finland & $1980-1996$ \\
France & $1980-1997$ \\
Greece & $1980-1997$ \\
Hungary & $1980-1998$ \\
Ireland & $1980-1996$ \\
Italy & $1980-1996$ \\
Luxembourg & $1980-1997$ \\
Netherlands & $1980-1997$ \\
Austria & $1980-1998$ \\
Portugal & $1980-1998$ \\
Spain & $1980-1997$ \\
Czech Republic & $1980-1998$ \\
Sweden & $1980-1996$ \\
United Kingdom & $1980-1998$ \\
\hline
\end{tabular}

specific intercept $\alpha_{i}$ This indicates that mortality decreases faster in countries that start with high mortality. Such a "catch up" phenomenon is to be expected. We were also interested in which countries have mortality rates that decreased significantly faster or slower than the average decrease over all countries after we took this "catch up" phenomenon into account. To estimate this, we refitted the model with an extra term $\gamma_{0} \hat{M}_{i, 1989}$, where $\hat{M}_{i, 1989}$ is the mortality rate in 1989 as estimated by a previous model, restraining the covariance of $\alpha_{\mathrm{i}}$ and $\beta_{\mathrm{i}}$ to 0 . This model was iteratively refitted until $\hat{M}_{i, 1989}$ no longer changed.

\section{RESULTS}

Avoidable mortality in absolute numbers declined between 1980 and 1997 in the selected European countries with the exception of Hungary (which showed an increase of 14.9 deaths/100 000 people over 10 years). Because of its exceptional position (fig 1), Hungary was excluded from the analysis. Non-avoidable mortality, in absolute numbers, declined faster than avoidable mortality $(-27.1 / 100000$ versus $-25.3 / 100000$ over 10 years), but the difference was not significant $(p=0.7)$. There was also no significant difference in the rate of decline between the first half of the period (1980-1989) and the second half (1989-1997) $(\mathrm{p}=0.07)$.

Six countries became EC members during the study period: Greece (1981), Portugal and Spain (1986), and Finland, Austria, and Sweden (1995). Political changes in the Czech Republic took place in 1989. We investigated whether the trends in all avoidable and non-avoidable mortality were different in Spain before and after 1986 and in the Czech Republic before and after 1989. Only for avoidable mortality in Spain were there statistically significant differences between the two periods - the decline was only present in the first period. There were not enough data available to make comparisons for Portugal, Greece, Finland, Austria, and Sweden for the periods before and after they joined the EC.

From the viewpoint of healthcare effectiveness, we are also interested in proportional declines in mortality because they give insight into the possible contribution of medical interventions to the mortality decline independently of the number of death causes. The rate of avoidable mortality between 1980 and 1997 diminished faster than the rate of non-avoidable mortality $(-2.4 \%$ year versus $-1.5 \% /$ year $)$. There is a significant difference between the trends in avoidable and non-avoidable mortality $(p=0.002)$. The annual decrease in the first half of the period (1980-1989) 

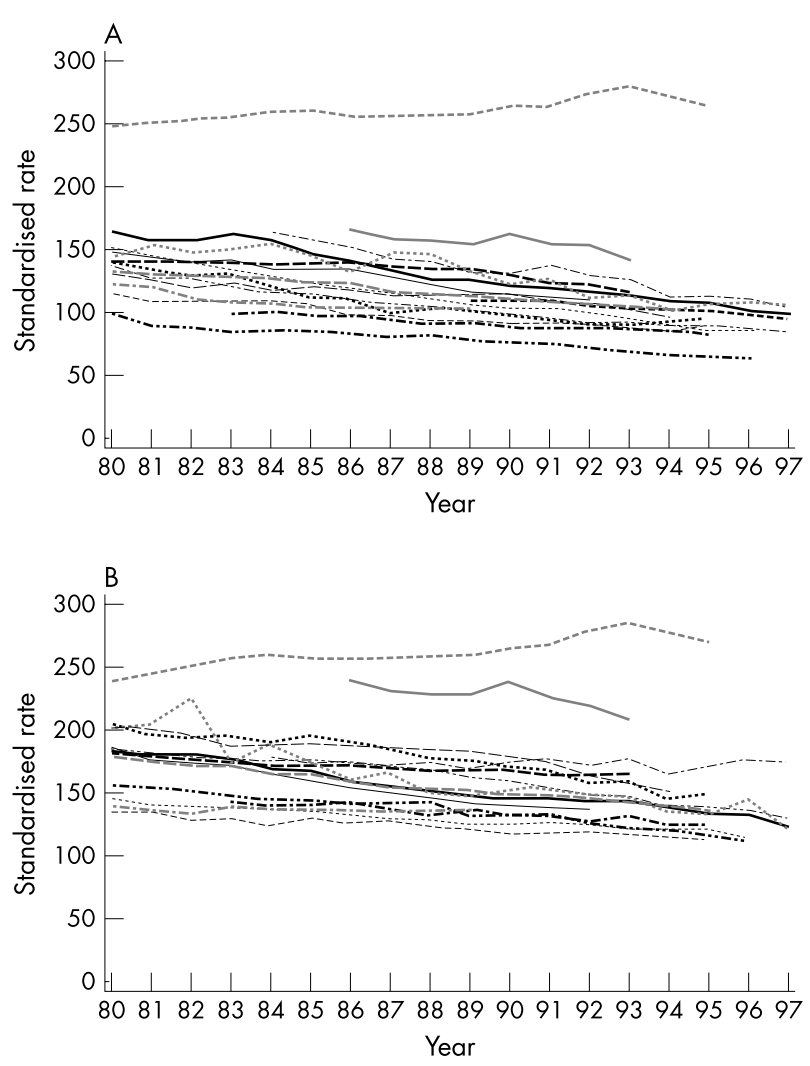

\begin{tabular}{|c|c|c|}
\hline $\begin{array}{l}\text { - Austria } \\
\text {-.-- Denmark } \\
\text {-..-. Germany } \\
\text {....... Ireland } \\
\text {-...- Netherlands } \\
\text {...... Sweden }\end{array}$ & 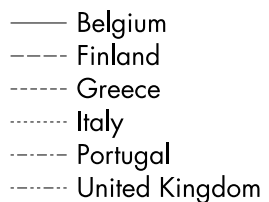 & 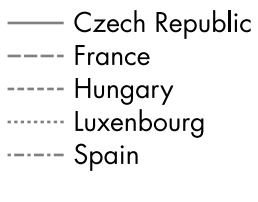 \\
\hline
\end{tabular}

Figure 1 Trends in 17 European countries, 1980-1997: (A) avoidable mortality; (B) non-avoidable mortality.

was $2.5 \%$ for avoidable mortality and $1.4 \%$ for non-avoidable mortality $(p=0.006)$. Between 1989 and 1997, the percentages were 2.5 and $1.8(\mathrm{p}=0.03)$. This means that the proportional decline of non-avoidable mortality accelerated in contrast with the decline of avoidable mortality, and that the difference between the declining rates decreased. We added the variation of decline between countries to the model, which statistically significantly improved the fit of the model for both periods and for both avoidable and nonavoidable mortality. This shows that the rates of decline differed by country (table 3 ).

We studied trends in individual causes in detail for the period 1989-1997. The starting levels in 1989 varied greatly, from 0.07 deaths/100 000 people for appendicitis to 19.3 deaths/100 000 people for lung cancer. On average, the largest decline (in absolute numbers) found in this period was for CVA/hypertension; and the smallest, for pneumonia/ influenza. Proportionally, the largest average declines in this period were found for chronic rheumatic heart disease, asthma/bronchitis/emphysema and tuberculosis, while small declines were found for leukaemia and skin cancer (table 4).

The largest trend variations between countries are for causes of death that are mainly or partly avoidable by primary prevention (motor vehicle accidents (fig 2), perinatal mortality, liver cirrhosis, lung cancer); the smallest, for causes that are amenable to curative intervention (appendicitis, testis cancer, Hodgkin's disease, and cholecystitis/ cholelithiasis). A significant correlation $(\mathrm{p}<0.05)$ exists between the starting level (1989) and the trend for five of the 19 causes of death (table 4). Visual inspection and calculation of the variance function show that the trends converged during the study period for these causes.

Statistically significant less than average declines of avoidable mortality were found for 10 countries, as were statistically significant more than average declines for another 10 countries (table 4). However, systematic geographical patterns were not directly visible. In the Czech Republic, Denmark, and Germany, more than average declines were found for causes mainly amenable to medical care (among which appendicitis and testis cancer). More than average declines for causes of death amenable to prevention (such as lung and skin cancer and liver cirrhosis) were found in Portugal, Spain, Italy, the United Kingdom, Ireland, and Finland. Less than average declines were found in Spain and Portugal for various neoplasms. Six countries showed less than average declines (the Netherlands, Sweden, Belgium, France, Greece, and Luxembourg), mainly for causes amenable to curative interventions (for example, CVA/hypertension and chronic rheumatic heart disease).

After adjustment for the starting level (for those causes of death for which a significant association exists between the trend and the starting level) only six countries remained for which significantly deviating trends were found (table 4). Only two of those countries showed less than average declines: the United Kingdom (for liver cirrhosis and perinatal mortality) and France (for breast cancer).

Ranking the countries revealed that the Czech Republic had the strongest trends in avoidable mortality (1989-1997). Despite differences in the declining rate of mortality, there were only moderate rearrangements in the ranking of avoidable causes of death (table 5). Greece and France were the only countries that fitted into more than one place, while Italy was the only country that rose by more than one place.

\section{DISCUSSION}

Up to date trend analyses generally show that, as expected, avoidable mortality declined much faster over the past decades than other causes of death. ${ }^{4-691317}$ Therefore, avoidable mortality was considered a valid indicator for the effectiveness of prevention and medical care. We found that the proportional change in avoidable mortality in the period 1989-1997 (-2.5\%/year) was indeed statistically significantly larger than the change in non-avoidable mortality $(-1.8 \%$ / year). However, the difference between $2.5 \%$ and $1.8 \%$ (although statistically significant) is much smaller than that reported by others who studied earlier periods within Europe. ${ }^{131618}$ Furthermore, the difference between the trends was found to decrease over time.

The comparatively slow decline of avoidable mortality in our study compared with that of previous studies may be primarily attributable to differences in data quality. Differences in diagnostic and certifying procedures complicate both national and international studies on mortality. They may have influenced the results for the individual causes of death. The aggregate measures of avoidable and non-avoidable mortality are probably less biased by these differences. ${ }^{11}$

A second possible explanation of the relatively slow decline of avoidable mortality in our study is that we included some avoidable causes of death (lung cancer, breast cancer, liver cirrhosis, and motor vehicle accidents) that were not included in most other studies on avoidable mortality (with the exception of Albert et al, ${ }^{17}$ Humblet et $a l,{ }^{6}$ and Simonato et $\left.a l^{11}\right)$. In our study, particularly lung cancer and breast cancer have relatively large impacts on the trend in total avoidable mortality as they represent rather large causes of 
Table 3 Annual decline of avoidable and unavoidable mortality in percentages, 19891997

\begin{tabular}{|c|c|c|c|c|}
\hline \multirow[b]{2}{*}{ Country } & $\begin{array}{l}\text { Avoidable } \\
\text { mortality }\end{array}$ & $\begin{array}{l}\text { Unavoidable } \\
\text { mortality }\end{array}$ & Avoidable mortality & Unavoidable mortality \\
\hline & \multicolumn{2}{|l|}{$1980-1989$} & \multicolumn{2}{|l|}{ 1989-1997 } \\
\hline 1 Austria & $3.3(2.4-4.1)$ & $2.4(2.0-2.7)$ & $3.0(2.6-3.4)$ & $2.0(1.5-2.5)$ \\
\hline 2 Belgium & $2.4(1.8-3.0)$ & $2.7(2.2-3.0)$ & $2.3(1.3-3.2)$ & $1.2(0.7-1.7)$ \\
\hline 3 Czech Republic & $2.1(1.4-2.8)$ & $1.8(0.8-2.6)$ & $2.8(1.4-4.1)$ & $2.7(1.4-3.8)$ \\
\hline 4 Denmark & $0.1(-0.4-0.5)$ & $1.1(0.8-1.4)$ & $2.9(2.1-3.5)$ & $1.5(0.8-2.2)$ \\
\hline 5 Finland & $2.0(1.3-2.7)$ & $0.9(0.4-1.4)$ & $3.9(3.0-4.6)$ & $3.3(2.7-3.8)$ \\
\hline 6 France & $2.1(1.9-2.3)$ & $1.7(1.4-1.9)$ & $2.2(1.8-2.6)$ & $1.6(1.2-2.0)$ \\
\hline 7 Germany & $2.5(0.0-4.9)$ & $1.5(0.0-2.9)$ & $1.7(1.3-2.1)$ & $2.5(1.9-3.0)$ \\
\hline 8 Greece & $2.5(2.1-2.8)$ & $1.0(0.7-1.2)$ & $1.4(0.7-2.0)$ & $0.8(0.4-1.3)$ \\
\hline 9 Ireland & $4.2(3.4-4.8)$ & $1.4(1.0-1.9)$ & $2.1(0.9-3.3)$ & $2.5(1.8-3.2)$ \\
\hline 10 Italy & $3.9(3.6-4.1)$ & $1.4(1.1-1.7)$ & $3.5(2.8-4.0)$ & $1.2(0.6-1.7)$ \\
\hline 11 Luxembourg & $0.9(0.3-1.5)$ & $2.3(1.5-3.0)$ & $3.0(2.0-4.0)$ & $1.9(1.0-2.8)$ \\
\hline 12 Netherlands & $1.7(1.0-2.4)$ & $1.2(0.5-1.9)$ & $1.6(1.1-2.2)$ & $1.4(0.9-1.8)$ \\
\hline 13 Portugal & $4.0(3.4-4.4)$ & $1.1(0.5-1.6)$ & $3.0(2.2-3.8)$ & $0.4(-0.2-1.0)$ \\
\hline 14 Spain & $2.6(2.1-3.1)$ & $0.0(-0.2-0.3)$ & $2.5(0.9-4.1)$ & $1.4(-0.1-2.8)$ \\
\hline 15 Sweden & $2.4(1.6-3.1)$ & $1.5(1.2-1.8)$ & $2.5(2.2-2.8)$ & $2.2(1.9-2.5)$ \\
\hline 16 United Kingdom & $3.1(2.7-3.5)$ & $1.2(1.0-1.5)$ & $2.1(0.7-2.0)$ & $2.6(2.2-2.8)$ \\
\hline Mean decline & $2.5(1.8-3.1)$ & $1.4(1.1-1.8)$ & $2.5(2.0-3.0)$ & $1.8(1.3-2.3)$ \\
\hline
\end{tabular}

death (29\% of all avoidable causes) that show a comparatively small decline.

Finally, the small and decreasing difference in decline between avoidable and non-avoidable mortality may be attributable to the fact that the non-avoidable mortality category increasingly includes death causes that have become avoidable over time. An example is coronary heart disease. In contrast with the time in which Rutstein et al composed their lists, it is now justifiable to include this disease in the avoidable group (as Humblet et al did), given the evidence of the effectiveness of the available prevention and treatment. At the same time, the "traditional" selections of avoidable

Table 4 Trends in avoidable mortality: mean decrease and variation between countries according to the model

\begin{tabular}{|c|c|c|c|c|c|c|c|}
\hline & $\begin{array}{l}\text { Mortality/ } \\
100000 \text { (0-64 } \\
\text { years of age) in } \\
1989 \text { (according } \\
\text { to the model) }\end{array}$ & $\begin{array}{l}\text { Decline in } 10 \\
\text { years; mortality/ } \\
100000 \text { (0-64 } \\
\text { years of age) }\end{array}$ & $\begin{array}{l}\text { Percentage } \\
\text { decline/ year } \\
\text { (0-64 years } \\
\text { of age) } \\
1989-1997\end{array}$ & $\begin{array}{l}\text { Variation } \\
\text { between } \\
\text { countries (SD) } \\
\text { in decline/ } \\
10 \text { year§ }\end{array}$ & $\begin{array}{l}\text { Decline } \\
\text { dependent on } \\
\text { starting level } \\
\text { (1989) } \\
\text { (p value) }\end{array}$ & $\begin{array}{l}\text { Countries showing } \\
\text { a more than } \\
\text { average decline } \\
(p<0.003) \ddagger\end{array}$ & $\begin{array}{l}\text { Countries showing } \\
\text { a less than } \\
\text { average decline } \\
(\mathrm{p}<0.003) \ddagger\end{array}$ \\
\hline Tuberculosis & 0.68 & 0.40 & 6.3 & 0.30 & 0.16 & Austria, Spain & $\begin{array}{l}\text { Netherlands, } \\
\text { Sweden }\end{array}$ \\
\hline Appendicitis & 0.07 & 0.03 (BS) & 2.0 & 0.06 & 0.05 & Czech Republic & Belgium \\
\hline Lung cancer & 19.3 & 2.1 & 1.0 & 2.6 & 0.13 & $\begin{array}{l}\text { Italy, United } \\
\text { Kingdom }\end{array}$ & Portugal, Spain \\
\hline Bladder cancer & 1.48 & 0.38 & 2.6 & 0.18 & 0.32 & & \\
\hline Liver cancer & 1.13 & 0.23 & 1.3 & 0.25 & $0.17^{*}$ & United Kingdom & France \\
\hline Testis cancer & 0.22 & 0.10 & 1.3 & 0.11 & 0.02 & $\begin{array}{l}\text { Czech Republic, } \\
\text { Denmark, Germany }\end{array}$ & \\
\hline Liver cirrhosis & 10.5 & 2.5 & 2.3 & 2.7 & 0.03 & Italy, Spain & United Kingdom \\
\hline Perinatal & 12.6 & 3.9 & 3.5 & 3.4 & 0.07 & $\begin{array}{l}\text { Czech Republic } \\
\text { Portugal }\end{array}$ & United Kingdom \\
\hline $\begin{array}{l}\text { Motor vehicle } \\
\text { accidents }\end{array}$ & 14.6 & 4.0 & 3.4 & 4.4 & 0.15 & $\begin{array}{l}\text { Finland, Portugal, } \\
\text { Spain }\end{array}$ & Czech Republic \\
\hline Skin cancer & 1.54 & 0.18 (NS) & 0.9 & 0.37 & 0.06 & Ireland & Greece \\
\hline Breast cancer & 10.0 & 1.32 & 1.3 & 0.98 & 0.03 & United Kingdom & France \\
\hline Cervix cancer & 1.33 & 0.35 & 2.4 & 0.38 & 0.13 & United Kingdom & Portugal, Spain \\
\hline Hodgkin's disease & 0.60 & 0.25 & 4.1 & 0.15 & 0.4 & & \\
\hline CVA/hypertension & 16.1 & 4.7 & 3.2 & 2.5 & 0.02 & $\begin{array}{l}\text { Czech Republic, } \\
\text { Portugal }\end{array}$ & $\begin{array}{l}\text { Netherlands, } \\
\text { Sweden }\end{array}$ \\
\hline $\begin{array}{l}\text { Asthma/bronchitis/ } \\
\text { emphysema }\end{array}$ & 4.1 & 2.4 & 6.3 & 1.7 & 0.007 & $\begin{array}{l}\text { Czech Republic, } \\
\text { Denmark }\end{array}$ & $\begin{array}{l}\text { France, Greece, } \\
\text { Spain }\end{array}$ \\
\hline $\begin{array}{l}\text { Cholelithiasis/ } \\
\text { cholecystitis }\end{array}$ & 0.20 & 0.09 (BS) & 2.3 & 0.16 & 0.05 & $\begin{array}{l}\text { Czech Republic, } \\
\text { Germany }\end{array}$ & \\
\hline Pneumonia/influenza & 2.77 & 0.02 (NS) & 1.1 & 0.97 & 0.9 & Austria, France $†$ & United Kingdom \\
\hline Leukaemia & 2.34 & 0.16 (NS) & 0.6 & 0.30 & 0.05 & Czech Republic & Spain \\
\hline $\begin{array}{l}\text { Chronic rheumatic } \\
\text { heart disease }\end{array}$ & 0.95 & 0.62 & 7.4 & 0.55 & 0.007 & $\begin{array}{l}\text { Czech Republic, } \\
\text { Spain }\end{array}$ & $\begin{array}{l}\text { Belgium, Greece, } \\
\text { Luxembourg }\end{array}$ \\
\hline $\begin{array}{l}\text { All avoidable } \\
\text { mortality }\end{array}$ & 101.1 & 24.2 & 2.4 & 8.8 & 0.03 & & $\begin{array}{l}\text { Greece, } \\
\text { Netherlands, } \\
\text { Sweden }\end{array}$ \\
\hline Other mortality & 171.9 & 30.5 & 1.5 & 17.1 & 0.03 & Finland & Greece, Portugal \\
\hline
\end{tabular}




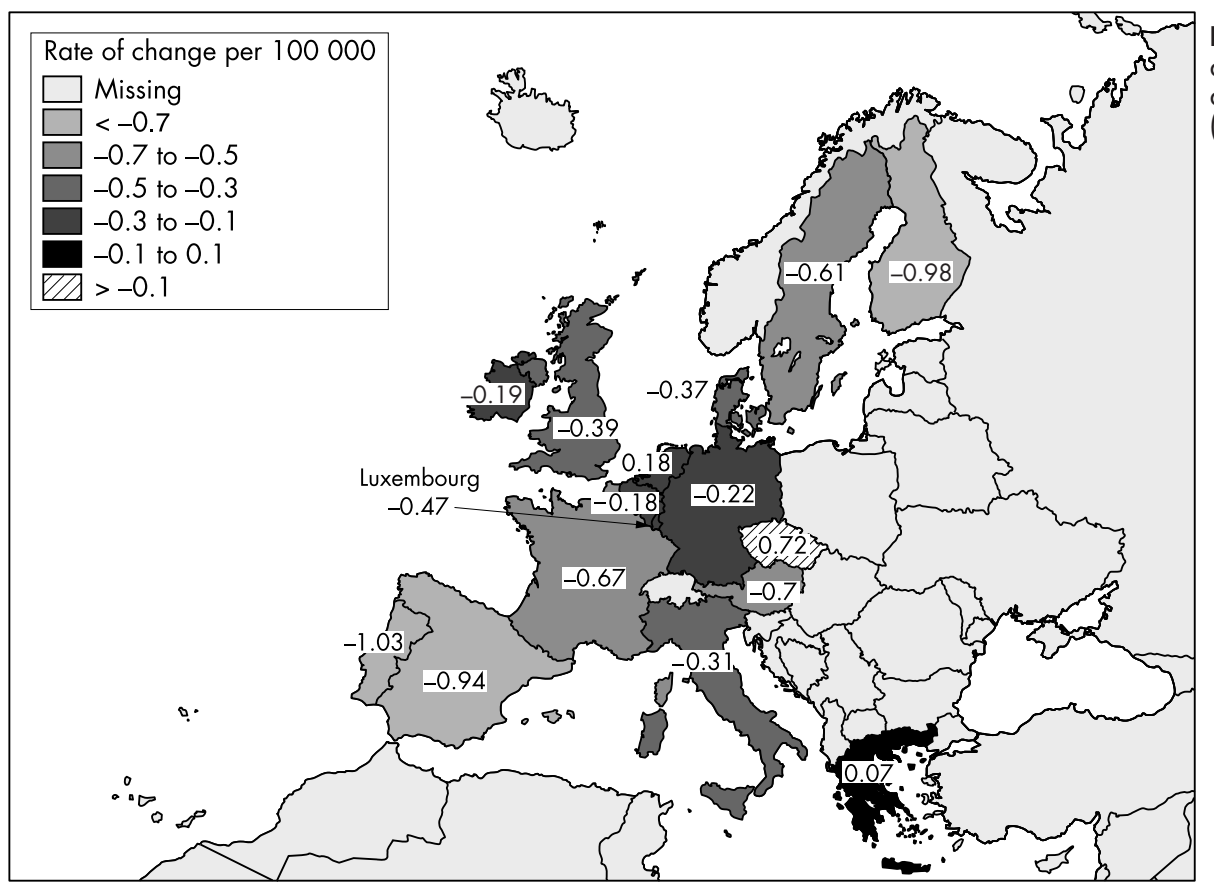

Figure 2 Proportional mortality decline per year for motor vehicle accidents among men and women (0-64 years) in the period 1989-1997.

causes of death may include causes for which it has become questionable whether improvements in medical care and prevention nowadays still contribute to their decline over time. For the "surgical" causes (such as appendicitis, cholecystitis, and cholelithiasis), for example, effective interventions were introduced long before 1980. Our suggestion for further work is to reconsider and standardise the selection of the current causes of death to be included in studies on avoidable mortality. This will improve the comparability of studies on avoidable mortality and the sensitivity of avoidable mortality to variations in the quality of health care. To define such a standard set of causes of death, a critical and systematic revision of Rutstein's lists is indicated.

The largest mortality trend variations in the countries studied are those for causes amenable to prevention; and the smallest, for causes amenable to curative care. The causes amenable to cure also show the largest percentage declines, a fact that has also been reported by others. ${ }^{911} 2021$ European countries in general probably reached more consensus about how to provide medical care than about methods for effective prevention. The use of standards and protocols in medical care may have played a part here. Converging trends were found for various causes of death, such as testis cancer, liver cirrhosis, breast cancer, CVA/hypertension and asthma/ bronchitis/emphysema, which may suggest that medical and preventive care is being increasingly provided for these diseases in a uniform way. None the less, the evolution of cause specific mortality depends not only on changes in the quality of medical care and prevention, but also on changes in the quality of mortality data (as already mentioned), on changes of incidence, severity and a variety of factors outside the medical care system. Further research is thus needed to find out what factors may have contributed to the variations of the trends within Europe.

The United Kingdom and France were the only countries showing less than average declines after adjustment for the starting level for liver cirrhosis, perinatal mortality (United

\begin{tabular}{|lll|}
\hline $\begin{array}{l}\text { Table } 5 \\
\text { and mortality levels in } 1989 \text { and } 1995\end{array}$ & \\
\hline $\begin{array}{l}\text { Ranking by mortality trend } \\
\text { (from most to least decline) }\end{array}$ & $\begin{array}{l}\text { Ranking by level in } 1989 \\
\text { (from lowest to highest level) }\end{array}$ & $\begin{array}{l}\text { Ranking by level in } 1995 \\
\text { (from lowest to highest level) }\end{array}$ \\
\hline Czech Republic & Sweden & Sweden \\
Portugal & Netherlands & Finland \\
Finland & Finland & Netherlands \\
Italy & Ireland & Ireland \\
Denmark & Greece & United Kingdom \\
Luxembourg & United Kingdom & Italy \\
Austria & France & Greece \\
Spain & Spain & Spain \\
Belgium & Germany & France \\
France & Italy & Germany \\
United Kingdom & Belgium & Belgium \\
Ireland & Austria & Austria \\
Sweden & Luxembourg & Luxembourg \\
Germany & Denmark & Denmark \\
Netherlands & Portugal & Portugal \\
Greece & Czech Republic & Czech Republic \\
\hline & \\
\hline
\end{tabular}




\section{Key points}

- Between 1980 and 1997, avoidable mortality declined in 15 European countries and the Czech Republic, but not in Hungary.

- The difference between the trends in avoidable mortality and non-avoidable mortality was small and declined over time.

- Various countries showed trends that deviated significantly from the mean trend. The largest trend variations existed for causes that are mainly or partly amenable to prevention.

- The selection of causes of death to be included in studies on avoidable mortality have to be standardised, for which a critical revision of Rustein's lists is indicated.

Kingdom) and breast cancer (France). The comparatively small decline of liver cirrhosis was preceded by increased alcohol consumption in the United Kingdom between 1970 and 1980. The prevalence of alcohol dependence has also risen fairly rapidly since $1991 .^{22}$ A possible factor in the comparatively slow decline of perinatal mortality in the United Kingdom is that more babies are born alive after comparatively short gestations. ${ }^{23}{ }^{24}$ However, birth weight is only one of the factors that may explain international variations in perinatal mortality. ${ }^{25}$ Finally, the comparatively slow decline of breast cancer mortality in France may be attributable to relatively unfavourable developments in the risk factors for breast cancer or the quality of interventions.

Hungary showed an increase in avoidable mortality between 1980 and 1997. Velkova et al (1997) also report relatively high levels of mortality attributable to causes amenable to medical intervention in countries of Central and Eastern Europe (including Hungary) compared with those in Western Europe. ${ }^{19}$ Their results suggest that the contribution of medical care to the gap in life expectancy may not be as limited as has often been asserted. Introducing effective strategies for prevention and improving the standards of medical care in the countries of Central and Eastern Europe may contribute to bridging the gap in health between Eastern and Western Europe.

In conclusion, this study indicates that the difference in decline between avoidable and non-avoidable mortality is small and it is diminishing. Effort is therefore needed to continue to reduce specific causes of avoidable mortality. Furthermore, some individual countries show comparatively unfavourable developments in avoidable mortality, which can be considered a signal pointing to possible unfavourable developments in the quality of prevention or medical care, or both. Research in these countries must unravel the causes of these trends in order to identify unfavourable developments. Finally, we suggest that the selection of the current causes of death be reconsidered and standardised for the purposes of studies on avoidable mortality. A critical revision of Rutstein's lists is indicated. The revised lists should contain all causes of death that are avoidable at the moment, given the available knowledge about prevention and medical care. The date when the cause of death became avoidable should be given for each cause on the lists. This effort will make avoidable mortality a more useful health outcome for monitoring the quality and effectiveness of health care in the 21 st century.

\section{ACKNOWLEDGEMENTS}

We would like to thank Willem Heemskerk for collecting and preparing the data, Gerda Doornbos and Cor de Lezenne Coulander for composing figure 2, and Johan Mackenbach for critically reading the manuscript.

\section{Authors' affiliations}

H F Treurniet, Department for Public Health Forecasting, National Institute for Public Health and the Environment, Bilthoven, Netherlands H C Boshuizen, Computerisation and Methodological Consultancy Unit, National Institute of Public Health and the Environment, Bilthoven, Netherlands

P P M Harteloh, Department of Health Policy and Management, Erasmus University, Rotterdam, Netherlands

\section{REFERENCES}

1 Rutstein DD, Berenberg W, Chalmers TC, et al. Measuring the quality of medical care: a clinical method. N Engl J Med 1976;294:582-9.

2 Rutstein DD, Berenberg W, Chalmers TC, et al. Measuring the quality of medical care: second revision of tables of indexes. N Engl J Med 1980;302:1146.

3 Treurniet HF, Looman CWN, Maas PJvan der, et al. Variations in 'avoidable' mortality: a reflection of variations in incidence? Int J Epidemiol 1999;28:225-32.

4 Tobias M, Jackson G. Avoidable mortality in New Zealand. Aust N Z J Public Health 2001;25:12-20.

5 Niti M, Ng TP. Temporal trends and ethnic variations in amenable mortality in Singapore 1965-1994: the impact of health care in transition. Int J Epidemiol 2001;30:966-73.

6 Humblet PC, Lagasse R, Levêque A. Trends in Belgian premature avoidable deaths over a 20 year period. J Epidemiol Community Health 2000;54:687-91

7 Holland WW, ed. The European Community atlas of 'avoidable death', Commission of the European Communities Health Services Research Series 3. Oxford: Oxford University Press, 1988.

8 Holland WW, ed. The European Community atlas of 'avoidable death', volume II, 2nd edn. Commission of the European Communities Health Services Research Series 9. Oxford: Oxford University Press, 1993.

9 Charlton JRH, Velez R. Some international comparisons of mortality amenable to medical intervention. BMJ 1986;292:295-300.

10 Poikolanen K, Eskola J. Health services resources and their relation to mortality from causes amenable to health care intervention: a cross-national study. Int J Epidemiol 1988;17:86-9.

11 Simonato L, Ballard T, Bellini P, et al. Avoidable mortality in Europe 19551994: a plea for prevention. J Epidemiol Community Health 1998;52:624-30.

12 Kunst AE, Looman CWN, Mackenbach JP. Medical care and regional mortality differences within the countries of the European Community. Eur J Population 1988;4:223-45.

13 Kjellstrand CM, Kovithavongs C, Szabo E. On the success, cost and efficiency of modern medicine: an international comparison. J Intern Med 1988;24:3-14.

14 D'après. United Nations World Population Prospects 1990. New York: United Nations, 1991.

15 Breslow NE, Day NE. Indirect standardisation and multiplicative models for rates, with reference to the age adjustment of cancer incidence and relative frequency data. J Chronic Dis 1975;28:289-303.

16 Mackenbach JP, Bouvier-Colle MH, Jougla E. "Avoidable" mortality and health services: a review of aggregate data studies. J Epidemiol Community Health 1990;44:106-11.

17 Albert X, Bayo A, Alfonso JL, et al. The effectiveness of health systems in influencing avoidable mortality: a study in Valencia, Spain, 1975-90. J Epidemiol Community Health 1996;50:320-5.

18 Carstairs V. Avoidable deaths in countries of the European Community and Scotland. Health Bull 1993;51:151-7.

19 Velkova A, Wolleswinkel-van den Bosch JH, Mackenbach JP. The East-West life expectancy gap: differences in mortality from conditions amenable to medical intervention. Int J Epidemiol 1997;26:75-84.

20 Poikolanen K, Eskola J. The effect of health services on mortality: decline in death rates from amenable and non-amenable causes in Finland 1969-1981. Lancet 1986;i:199-202.

21 Mackenbach JP, Loomans CWN, Kunst AE, et al. Post-1950 mortality trends and medical care: gains in life expectancy due to declines in mortality from conditions amenable to medical intervention in the Netherlands: a comparison of 4 time-periods. J Epidemiol Community Health 1988;42:325-32.

22 Eurocare. United Kingdom - country profile. Alcohol consumption and prevalence. http://www.eurocare.org/ profiles/uk01.htm\#anchor5004805

23 OECD. OECD Health Data 2000. Available on CD-ROM. Version 07/15/00. Paris: 2000.

24 Anonymous. European Community collaborative study of outcome of pregnancy between 22 and 28 weeks' gestation. Working Group on the Very Low Birthweight Infant. Lancet 1990;336:782-4.

25 Richardus JH, Graafmans WC, Verloove Vanhorick SP, et al. The perinatal mortality rate as an indicator of quality of care in international comparisons. Med Care 1998;36:54-66. 